\title{
The Brazilian Unified Health System Organization of Ser- vices: Challenges and Demands in Times of COVID-19
}

\author{
Lucas Soares Bezerra, ${ }^{1 *}$ Patrícia Virgínia Bastos de Figueiredo, ${ }^{2}$ Bruna Cavalcanti de Siqueira Leite, ${ }^{2}$ Caio Porciún- \\ cula Teixeira Basto ${ }^{3}$
}

${ }^{1}$ Postgraduate Program in Therapeutic Innovation, Universidade Federal de Pernambuco, Brazil

${ }^{2}$ Medical School, Centro Universitário Maurício de Nassau, Brazil

${ }^{3}$ Medical Residency Program in General Surgery, Hospital dos Servidores de Pernambuco, Brazil

\begin{abstract}
In view of the COVID-19 pandemic, the organization of the services of the Brazilian Unified Health System (SUS) played a fundamental role based on aspects such as the structuring of services and levels of health care, hiring and training of professionals, allocation of resources, as well as such as the offer and access to hospital beds. This essay seeks to discuss how the current dynamics of SUS in relation to the organization of services has influenced the performance of this system in coping with the pandemic of COVID-19.
\end{abstract}

Keywords: Unified health system, Pandemics, Coronavirus infections

\section{Introduction}

An important political-social challenge faced since 2020 has been the confrontation of the COVID-19 pandemic. This fact has further intensified the inequities in access to health throughout the world, including in countries with universal health systems, even though these are constantly pointed out as the most adequate in responding to social demands. ${ }^{1}$ In Brazil, the Unified Health System (SUS), a reflection of the understanding of health as a social right from the Federal Constitution of 1988 and the enactment of Law $8.080 / 1990,{ }^{2}$ has faced strong criticism and questioning about its role in the face of demands of this pandemic.

Among the main aspects to be evaluated when discussing the role and action of the SUS in face of the health crisis caused by COVID-19, the organization of health services stands out. This mechanism has been one of the pillars of economics in health, since it is based on it that we are able to analyze both the quality of services in different health organizations and the use and allocation of their resources. ${ }^{3}$
In the COVID-19 pandemic, some measures related to the organization of services were taken, such as the expansion of beds in the Intensive Care Unit (ICU) and infirmary from the creation of campaign hospitals, ${ }^{4}$ the increase in the availability of professionals from health from the advancement of graduation from those close to the end of graduation, ${ }^{5}$ and also by the organization of care for cases of suspected diagnosis according to the different levels and units of health care. ${ }^{6}$

Considering this discussion, this text aims to discuss how the current dynamics of the SUS in relation to the organization of services have influenced the performance of this system in facing the COVID-19 pandemic. In this treatment, an updated literature review was carried out, using data and arguments from relevant studies.

\section{Structure of the System According to Health Care Levels} and Units

Healthcare networks are an alternative in the planning of health policies and have different functions according to the level of care

\begin{tabular}{l|l|}
\hline Quick Response Code: & *Corresponding author: Lucas Soares Bezerra, Programa de Pós Graduação em Inovação Ter- \\
apêutica (PPGIT), Centro de Biociências, Universidade Federal de Pernambuco, Recife, Brazil \\
Received: 22 June, 2021
\end{tabular}


and complexity assessed. The very idea of "network" points to a mechanism of integration and interdependence, in which its different units and levels communicate to allow the patient's access to the health system. ${ }^{7}$

In face of the pandemic, the health system had the role of restructuring the flow of care, defining the function of each unit, as well as from the creation of new specialized centers. ${ }^{4,6}$

The primary care units had as their main function the care of non-serious cases of COVID-19, as well as in the education of the population by encouraging means of reducing the transmission of the infectious agent and identifying situations of social vulnerability. ${ }^{6}$ From the work carried out in primary care, there was a reduction in the flow of patients seeking emergency units and hospitals, in response to improved care for more complex cases and a reduction in the flow of disease transmission. Despite this, one of the main limitations faced by primary care was the difficulty in directing hospital beds for more severe cases. ${ }^{6,8}$

Most outpatient care units were shut down during the early stages of the pandemic. This fact resulted in the destabilization and poor therapeutic control of several patients with chronic diseases, such as hypertension, heart failure, asthma, HIV/AIDS and diabetes. As these are risk factors with a worse prognosis in Acute Respiratory Syndrome secondary to COVID-19, this problem contributed to the increase in mortality rates and hospital admissions in the country, mainly affecting the most vulnerable populations. ${ }^{9}$

One measure adopted to try to minimize the flow of care in emergency units and to continue the outpatient care was that of teleservices, ${ }^{6}$ which is already widely used in diagnostic and support units, mainly in the act of providing reports of imaging exams. The Federal Council of Medicine, for example, regulated online consultations in the area from Resolution No.56 of April 1, 2020. ${ }^{5}$ While this mechanism brings an integration of the technological process to the health system, it exposes social inequalities of the country, since a good portion of the population does not have access to electronic devices and internet, and these advances in telehealth are neglected.

\section{The Role of Bed Regulation Committees}

The Bed Regulation Committee is the body responsible for organizing the distribution of beds in health centers, which includes hospitalization in different sectors (such as the infirmary and ICU) and conducting emergency tests (such as Computed Tomography and Upper Digestive Endoscopy). Its importance lies mainly in the role of analyzing and managing patients' access to health services from the SUS. During the pandemic, however, problems with the flow of access to beds were noticed, as well as their insufficiency. ${ }^{6}$

Among the strategies that could be implemented in the regulation of beds is the optimization of the transfer of patients between levels of the health care network, since the affected patients have the characteristic of rapid progression in severe cases, ${ }^{10}$ being directly harmed with the delay in transferring to ICU beds. It is also necessary to expand the number of professionals who work at the bed regulation center, since the framework was already inefficient in view of the demand for connections even before the pandemic. ${ }^{8}$

\section{Offer of Infirmary and ICU Beds}

The expansion of inpatient spaces for cases of moderate or high severity depended on the structural expansion of existing health centers, the construction of new hospital units and the purchase of spaces in private services. ${ }^{5}$

One of the main difficulties pointed out, either due to the demand for transfer from the Emergency Care Units (UPAs) or from the basic health units, was that the patients needed specific beds, since COVID-19 and non-COVID-19 patients could not be mixed in the same hospital environment. ${ }^{6}$ This restriction in access to beds was one of the reasons for the Regional Council of Medicine of Pernambuco to guide, based on CREMEPE recommendation No. 05/2020, medical professionals to use the Unified Score for Prioritization (EUP-UTI), which uses clinical and laboratory parameters to define which patients should have priority for available ICU beds. ${ }^{11}$

The Brazilian health system did not show enough structure to handle the increased demand for ICU beds. Baptista et al. ${ }^{4}$ points out that in just one month, with $0.1 \%$ of the Brazilian population infected, these beds would already be overloaded and, considering the percentage of $1 \%$ per month in each microregion, the system would collapse with more than half of these regions operating in addition to its structural capacity.

The distance for specialized care is also an important point, since according to Noronha et al. ${ }^{10}$ for $8 \%$ of Brazilian municipalities it is necessary to travel a distance greater than $240 \mathrm{~km}$ to have access to an ICU bed. Even using the capacity of the public and private sector combined, this problem would be repeated even in macro-regions, highlighting the need to reduce speed and flatten the contagion curve.

As with the other indicators covered in the work, the number of beds was also presented as insufficient before COVID-19. In a survey carried out by Goldwasser et al. ${ }^{8}$ between 2010 and 2011 a total of 33,101 medical requests were verified for an offer of only 268 ICU beds in Rio de Janeiro. Considering an average hospital stay of 11.3 days, 595 beds would be needed, almost double of the number available.

\section{Availability of Professionals}

During the pandemic 5,811 places were offered by the Ministry of Health for medical doctors working in primary care. These professionals were distributed in 1,864 municipalities, including indigenous areas. ${ }^{5}$

One of the measures adopted by the country was the advancement of university degrees in different health courses (Nursing, Pharmacy, Physiotherapy and Medicine) of those in the final stages of training. ${ }^{5}$ Despite being a strategy that increased the number of health professionals in the fight against COVID-19, there is the problem of lack of training and technical knowledge in relation to highly complex patients. It was not uncommon to see several of 
these recent graduates working directly in ICUs instead of being relocated to less complex levels, as in primary care.

Another point that affected the organization of health services was the high rate of virus contagion among health professionals. This public tends to have three times more chances of contamination than the general population, ${ }^{12}$ being even worse when subjected to work in environments with overcrowding and lack of protective equipment.

\section{Conclusion}

Despite the important role of social inclusion presented by the SUS, we observe numerous challenges in the organization of services, such as: fragmentation of public policies, inadequate allocation of resources, flow problems in the transfer of patients to high complexity, low technical and welcoming quality of services and insufficient inpatient beds. Such weaknesses seem to have been more strongly demarcated given the increased demand for these services in the COVID-19 pandemic.

\section{Acknowledgments}

None.

\section{Funding}

None.

\section{Conflicts of Interest}

Author declares that there is no conflict of interest.

\section{References}

1. Miranda GMD, Mendes A da CG, Silva ALA da. O desafio da organização do Sistema Único de Saúde Universal e resolutivo no pactofederativo Brasileiro. Saude e Soc. 2017;26:329-335.
2. Brasil. Dispõesobre as condições para a promoção, proteção e recuperação da saúde, aorganização e o funcionamento dos serviçoscorrespondentes e dáoutrasprovidências. 1990.

3. Viacava F, De Oliveira RAD, Carvalho C de C, et al. SUS: Supply, access to and use of health services over the last 30 years. Cienc e SaudeColetiva. 2018;23:1751-1762.

4. Barbosa Baptista A, Vieira Fernandes L. Covid-19, Análise Das Estratégias De Prevenção, Cuidados E Complicações Sintomáticas. Rev Desafios. 2020;7:38-47.

5. Oliveira WK de, Duarte E, França GVA de, et al. Como o Brasilpode deter a COVID-19. EpidemiolServSaude. 2020;29:e2020044.

6. Daumas RP, Silva GAE, Tasca R, et al. 0 papel da atençãoprimáriana rede de atençãoàsaúde no Brasil: limites e possibilidades no enfrentamento da COVID-19. Cad Saude Publica. 2020;36:e00104120.

7. da Silva SF. Organização de redes regionalizadas e integradas de atençãoàsaúde: Desafios do Sistema Único de Saúde (Brasil). Cienc e SaudeColetiva. 2011;16:2753-2762.

8. Goldwasser RS, Lobo MS de C, de Arruda EF, et al. Difficulties in access and estimates of public beds in intensive care units in the state of Rio de Janeiro. Rev Saude Publica. 2016;50:1-10.

9. Sánchez A, Simas L, Diuana V, et al. COVID-19 in prisons: An impossible challenge for public health? Cad Saude Publica. 2020;36(5):e00083520.

10. De Souza Noronha KVM, Guedes GR, Turra CM, et al. The COVID-19 pandemic in Brazil: Analysis of supply and demand of hospital and ICU beds and mechanical ventilators under different scenarios. Cad Saude Publica. 2020;36:1-17.

11. Pernambuco I para R de R e D de. COVID-19: orientações para profissionais de saúde. $11^{\text {th }}$ ed. 2020 .

12. Barroso B, Souza M, Bregalda M, et al. Saúde do trabalhadorem tempos de covid-19: reflexõessobresaúde, segurança e terapiaocupacional. Cad Bras Ter Ocup. 2020;1-14. 